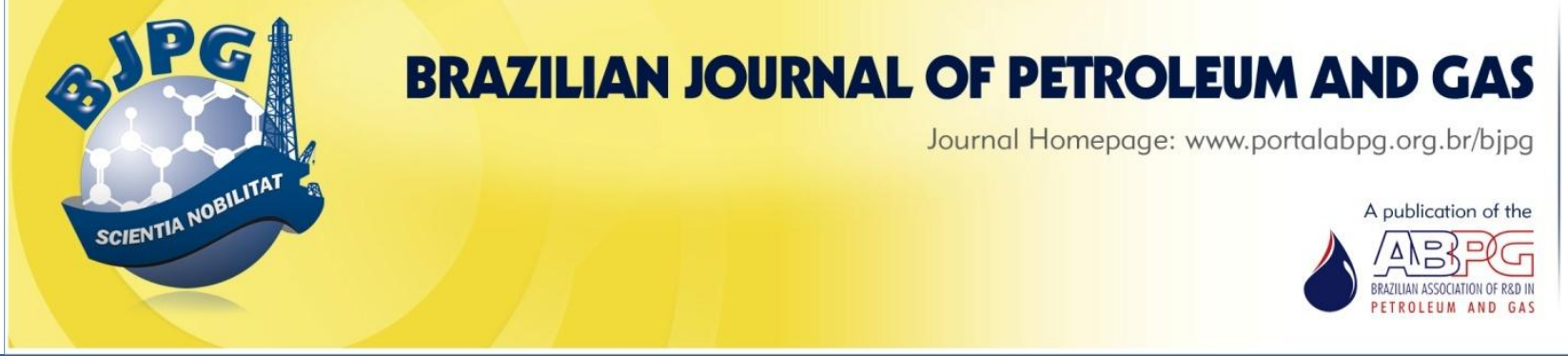

\title{
USE OF PROTIC IONIC LIQUID ([DETA][Hx]) AS CO-SOLVENT IN BIODIESEL PRODUCTION
}

\author{
${ }^{a}$ Trindade, M. E. J.; ${ }^{\text {a }}$ Mattedi, S.; ${ }^{\text {a }}$ Simonelli, G.; ${ }^{\text {a Santos, L. C. L. }}{ }^{1}$ \\ ${ }^{a}$ Federal University of Bahia, Graduate Program in Chemical Engineering, Salvador -BA, Brazil
}

Received: 27.11.2018 / Revised: 08.03.2019 / Accepted: 14.03.2019 / Published on line: 03.04.2019

\begin{abstract}
The need to develop sustainable alternative energy resources becomes an imperative as conventional energy sources are depleted. Ionic liquids (ILs) have acquired notoriety in several applications because of their interesting characteristics, such as favoring solubilization in organic substances, and presenting low surface tension and volatility. Aprotic ionic liquids (AILs) are used commonly as catalysts in biodiesel production. To achieve good results, considerable amounts of these compounds must be used in the reaction, which may affect the feasibility of the process due to its high cost. In this context, protic ionic liquids (PILS) may represent a less expensive alternative to traditional catalysts. When examining the surfactant activity of the ILs, one can observe that low concentrations can be applied to improve the yield of the reaction. Therefore, this study evaluates the use of diethylenetriammonium hexanoate $([D E T A][H x])$, a protic ionic liquid, as a co-solvent in the alkaline transesterification of soybean oil. The research presented satisfactory results, indicating that the use of small amounts of co-solvents enhances biodiesel yield in $8.14 \%$, reaching around $96 \%$ with only $3 \%(\mathrm{w} / \mathrm{w})$ of [DETA] [Hx] in 60 minutes of reaction, meeting the specifications of European (EN 14214), American (ASTM D6751), and Brazilian (ANP 45/2014) standards.
\end{abstract}

\section{KEYWORDS}

biodiesel; ionic liquid; transesterification; basic catalysis; co-solvent

\footnotetext{
${ }^{1}$ To whom all correspondence should be addressed.

Address: Federal University of Bahia, Graduate Program in Chemical Engineering, Rua Professor Aristídes Novis 2, Federação Escola Politécnica da UFBA $-2^{\circ}$ andar, Salvador, Bahia, Brazil.

Zip Code: 40210-630 Phone number: +55 71 99239-5165 | e-mail: Iclsantos@ufba.br doi:10.5419/bjpg2019-0006
} 


\section{INTRODUCTION}

The increase in global demand for fuel and energy associated with the indiscriminate use of its derivatives from non-renewable sources favors the emission of greenhouse gases that cause climate change and increase global warming. Biodiesel research has been intensified in recent years due to the great need for fuels allied with environmental issues and the continuous search for energy independence (Basha et al., 2009).

Biodiesel is a renewable fuel that has emerged as an alternative to replace diesel oil in compression ignition engines, and can be produced by different sources of triglycerides (ANP, 2018). Currently, the most used production process for obtaining high quality biodiesel is the transesterification of vegetable oils or animal fats, which consists in a reaction of triglycerides with short chain alcohol in the presence of a homogeneous or heterogeneous catalyst to obtain alkyl esters and glycerol as a by-product (Encinar et al., 2016).

Brazil is one of the world's leading producers of biodiesel. The Country uses primarily soybean oil as raw material, followed by bovine tallow, and waste cooking oil (ANP, 2018). The type of alcohol used in the process influences both the kinetics and the product yield. Typically, methanol is applied because of its physicochemical properties, low cost, moderate reaction conditions, and easy phase separation. Basic homogeneous catalysis provides softer reaction conditions, lower reaction time, and favors the achievement of high yields. However, basic catalysts must be used in its anhydrous form because the water contributes to saponification, which is an undesirable reaction, since the soap decreases biodiesel yield and inhibits the separation of alkyl esters and glycerol (Knothe \& Razon, 2017; Van Gerpen, 2005).

Ionic liquids (ILS) are organic salts that have a melting point generally below $100{ }^{\circ} \mathrm{C}$ (Andreani \& Rocha, 2012). ILs have been recognized widely as a novel chemical compound because of their interesting properties, which are capable of revolutionizing numerous chemical processes (Muhammad et al., 2015). Among several characteristics presented by ILs, one can highlight the possibility of being projectable to meet different needs, its moderate surface tension, biodegradability, low toxicity, good organic and inorganic solubility, low volatility, and good thermal and chemical stability (Olivier-Bourbigou et al., 2010).

ILs are excellent catalysts in biodiesel production due to some of their properties such as being easier to separate, producing low amounts of waste water, being less corrosive, recyclable and applicable in continuous processes (Muhammad et al., 2015). Many authors have investigated the use of aprotic ionic liquids (AILs) as catalysts to achieve high yields of biodiesel. For this reason, catalysis with acid AlLs is preferred due to its high thermal stability, high acidity accompanied by minimal discharge of dangerous gases, and the catalyst can be reused several times (Ghiaci et al., 2011; Rafiee \& Mirnezami, 2017; Vafaeezadeh \& Alinezhad, 2016). Recently, protic ionic liquids (PILs) have been considered more attractive than aprotic ones because of their more advantageous properties, such as the ability to promote an extensive network of hydrogen bonds, greater simplicity of synthesis, and low cost (Pinto et al., 2015).

The surfactant characteristic of ionic liquids favors its use as co-solvent, since there is a strengthening in the mass transfer of immiscible liquids, thus, promoting the dissolution between alcohol and oil at low temperatures, better separation between product and by-product, greater reaction rate and possibility of recovery and reuse (Encinar et al., 2016). It is believed that the ionic liquid containing hydrophobic regions has an association with the alkyl chains of the oil, as it provides energy to drive the biodiesel out of the phase with the co-solvent. Although the ionic liquid is present in small amounts in the reaction medium, it is possible to verify the selectivity increase and the reaction rate improvement (Muhammad et al., 2015, Olivier-Bourbigou et al., 2010, Thanh et al., 2013). Ruzich and Bassi (2010) evaluated the use of AIL 1-butyl-3-methyl imidazolium hexafluorophosphate ([BMIM] $\left.\left[\mathrm{PF}_{6}\right]\right)$ as a co-solvent in biodiesel production via enzymatic catalysis. The maximum yield in ester content found was $80 \%$ of biodiesel with $4 \mathrm{~mL}$ of co-solvent in $6 \mathrm{~h}$ of reaction at $55^{\circ} \mathrm{C}$.

Considering the lack of studies exploring the application of protic ionic liquid as co-solvent in the alkaline transesterification of soybean oil in 
biodiesel, this work has the objective of investigating if there is an improvement of biodiesel mass yield produced from the use of PIL [DETA] [Hx] as co-solvent.

\section{MATERIALS AND METHODS}

The materials used for biodiesel production in laboratory-scale were Soya ${ }^{\circledR}$ soybean oil, methanol (Synth, purity of 99.8\%, CAS 67-56-1), and potassium hydroxide (Sigma-Aldrich, purity of $85 \%$, CAS 1310-58-3). The protic ionic liquid used as cosolvent in this process was diethylenetriammonium hexanoate ([DETA][Hx]). To synthesize it, we used diethylenetriamine (Sigma-Aldrich, purity of 99\%, CAS 111-40-0) and hexanoic acid (Merck, purity of $98 \%$, CAS 142-62-1) as compounds.

\subsection{Soybean oil and biodiesel characterization}

Tests of acid value, humidity, kinematic viscosity at $40{ }^{\circ} \mathrm{C}$, and specific gravity at $20^{\circ} \mathrm{C}$ were carried out to promote the physicochemical characterization of soybean oil. Acid value and humidity are fundamental parameters to ensure the quality and the good state of conservation of vegetable oils. The acid value was determined by volumetric titration, based on ABNT NBR 11115 (2014) standard. The humidity was analyzed using the gravimetric method, following ANVISA's (2008) procedure. All experiments were performed in triplicate.

Specific gravity and kinematic viscosity analyses were carried out for oil and biodiesel using a SVM 3000 Viscometer, based on ASTM D4052 (2016) and ASTM D445 (2017) methods, respectively. To examine the structure of soybean oil and biodiesel produced, the infrared spectroscopy (FTIR) technique was used by infrared spectrophotometer with IRPrestige-21 Shimadzu Fourier Transform, with infrared spectrum in the region of 4000 to 400 $\mathrm{cm}^{-1}$ analyzed on $\mathrm{KBr}$ pellets.
For biodiesel, it was performed a visual inspection to verify if the samples were clear and free of impurities. Flashpoint analysis by Petrotest PM4 equipment were also carried out based on the ASTM D93 (2016).

The results of biodiesel characterization tests were compared to European (EN 14214, 2012), American (ASTM D6751, 2007), and Brazilian standards (ANP 45/2014, 2014), which specify biodiesel quality parameters for its commercialization.

\subsection{Synthesis and characterization of [DETA][Hx]}

lonic liquids are synthesized by an acid-base neutralization reaction, resulting in a liquid salt of the base used (Olivier-Bourbigou et al., 2010). To synthesize [DETA][Hx], $1 \mathrm{~mol}$ of the diethylenetriamine base and $3 \mathrm{~mol}$ of hexanoic acid were used to guarantee a complete reaction. In this system, aliquots of hexanoic acid were dripped slowly to diethylenetriamine under constant stirring at $300 \mathrm{rpm}$. Throughout the reaction it is important to maintain adequate temperature control around $40{ }^{\circ} \mathrm{C}$, since this reaction is exothermic (Pinto et al., 2015). Ionic liquids formed from ammonium salts tend to be strongly hygroscopic and may contain a considerable amount of water, which may be the impurity generated during the reaction or absorbed from the environment (Santos et al., 2016). Figure 1 illustrates the chemical reaction to synthesize [DETA] $[\mathrm{Hx}]$.

The ionic liquid was characterized by specific gravity, kinematic viscosity, surface tension, and infrared spectroscopy tests. The specific gravity and kinematic viscosity of the $[\mathrm{DETA}][\mathrm{Hx}]$ were obtained by Viscometer SVM 3000, based on ASTM D4052 (2016) and ASTM D445 (2017) methods, respectively. The surface tension was analyzed by Kruss K20 tensiometer, based on ASTM D971 (2012) method. For [DETA][Hx] structure analysis, the technique of Infrared Spectroscopy (FTIR) was used by infrared spectrophotometer with

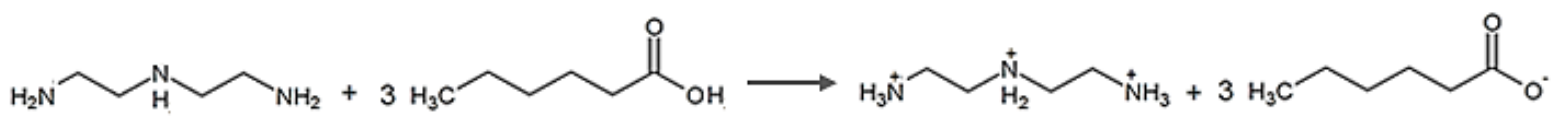

Figure 1. Reaction to synthesize diethylenetriammonium hexanoate [DETA][Hx]. 
Table 1. Soya ${ }^{\circledR}$ soybean oil physicochemical characterization.

\begin{tabular}{llll}
\hline Experiments & Analysis & \multicolumn{2}{l}{ Reference Values } \\
\hline $\begin{array}{l}\left.\text { Acid Value (mgKOH. }{ }^{-1}\right) \\
\text { Humidity (\%) }\end{array}$ & $0.28 \pm 0.01$ & 0.42 & (Keera et al., 2011) \\
$\begin{array}{l}\text { Kinematic viscosity at } 40^{\circ} \mathrm{C} \\
\left(\mathrm{mm}^{2} \mathrm{~s}^{-1}\right)\end{array}$ & $31.06 \pm 0.02$ & 32.90 & $\begin{array}{l}\text { (Leung et al., 2010) } \\
\text { (Lima et al., 2012) }\end{array}$ \\
Specific gravity at $20^{\circ} \mathrm{C}\left(\mathrm{g} . \mathrm{cm}^{-3}\right)$ & $0.920 \pm 0.001$ & 0.933 & $\begin{array}{l}\text { (Keera et al., 2011; Leung et al., } \\
\text { 2010) }\end{array}$ \\
\hline
\end{tabular}

IRPrestige-21 Shimadzu Fourier transform, with infrared spectrum in the region of 4000 to $400 \mathrm{~cm}^{-1}$ analyzed on $\mathrm{KBr}$ pellets.

\subsection{Experimental procedures to produce biodiesel}

To promote transesterification reactions on bench scale, it was used a condenser coupled to a thermostatic bath. First, $100 \mathrm{~g}$ of soybean oil were placed in a flat bottom flask. Separately, the mixture to be added to the oil was prepared. [DETA] $[\mathrm{Hx}]$ was weighed at 1,2 , and $3 \%(\mathrm{w} / \mathrm{w})$ related to the oil mass and $1.5 \%(\mathrm{w} / \mathrm{w}) \mathrm{KOH}$, these were added to $39.8 \mathrm{~mL}$ of methanol (molar ratio 9:1 MeOH/oil). The reaction was run in 60 minutes at $60{ }^{\circ} \mathrm{C}$ under constant stirring. At the end of the reaction, the product was transferred to a separatory funnel and set for $24 \mathrm{~h}$. Glycerol was then separated from biodiesel, and four wash cycles were performed with distilled water at $80^{\circ} \mathrm{C}$ to remove remaining alcohol, catalyst, ionic liquid, and glycerol. The biodiesel produced was placed in an oven at $105^{\circ} \mathrm{C}$ for $3 \mathrm{~h}$. Finally, the calculation of the mass yield was performed from Eq. (1) (Mohamad et al., 2017; Moro et al., 2017; Santos et al., 2013):

$$
\text { Yield }(\%)=\frac{\text { Biodiesel weight }(g)}{\text { Oil weight }(g)} \times 100 \%
$$

\section{RESULTS E DISCUSSION}

\subsection{Soybean oil characterization}

In an alkaline transesterification reaction there are limitations on the use of raw materials containing high free fatty acids and water. It is necessary to ensure that the oil is suitable for being used in this process. Soybean oil was characterized by tests of acid value, humidity, kinematic viscosity at $40{ }^{\circ} \mathrm{C}$, and specific gravity at $20{ }^{\circ} \mathrm{C}$. Table 1 presents the results of the analysis performed, showing a compliance with data found in the literature, indicating that soybean oil met the quality standards. Oil humidity should be low to avoid triglycerides hydrolysis and free fatty acid formation, which are detrimental to the good performance of alkaline transesterification reaction of oil, since soap can be produced as a result of the free fatty acids and basic catalysts reaction (Knoth \& Razon, 2017; Varatharajan \& Pushparani, 2018).

\subsection{Ionic liquid characterization}

Diethylenetriammonium hexanoate ([DETA][Hx]) presented the following properties at $60{ }^{\circ} \mathrm{C}$ : specific gravity of $974.5 \mathrm{~kg} \cdot \mathrm{m}^{-3}$, kinematic viscosity of $388.72 \mathrm{~mm}^{2} . \mathrm{s}^{-1}$, and surface tension of $24.3 \mathrm{mN} \cdot \mathrm{m}^{-1}$. The analysis of infrared spectroscopy confirmed the presence of [DETA][Hx] functional groups. Figure 2 illustrates the IR spectra of this ionic liquid.

In ionic liquid based on ammonium neutralization, the spectrum must present the cation band, corresponding to the $\mathrm{N}-\mathrm{H}$ structure of primary amines, which is present in the band around $3600-3200 \mathrm{~cm}^{-1}$ and is reproduced in the range of $1640-1550 \mathrm{~cm}^{-1}$. The peak of the anion range is visualized by the carbonyl, elongation $\mathrm{C}=\mathrm{O}$ of the carboxylic acid group, exhibited in the range of $1850-1610 \mathrm{~cm}^{-1}$ and replicated in the range $3400-2500 \mathrm{~cm}^{-1}$. Complex compounds, such as ionic liquids, may present overlaps between the cation and anion bands. For this reason, it is important to detect other bands to confirm different structures present in the compound. The bands between $1300-1250 \mathrm{~cm}^{-1}$ are assigned to $\mathrm{C}-\mathrm{O}$ bond of carboxylic acids. The peak between $3000-2800 \mathrm{~cm}^{-1}$ and ratified in the range of $1450-1375 \mathrm{~cm}^{-1}$ refers to the $\mathrm{C}-\mathrm{H}$ sp3 bonds of the alkyl chain of the anion and the ethyl cation groups (Pinto et al., 2015). 


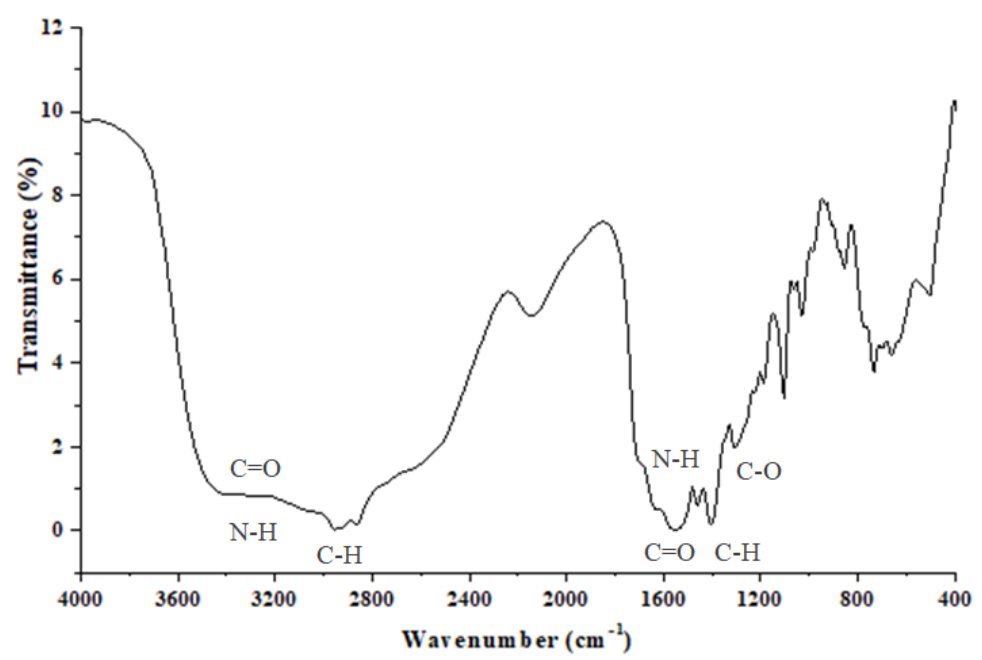

Figure 2. FTIR of diethylenetriammonium hexanoate [DETA][Hx].

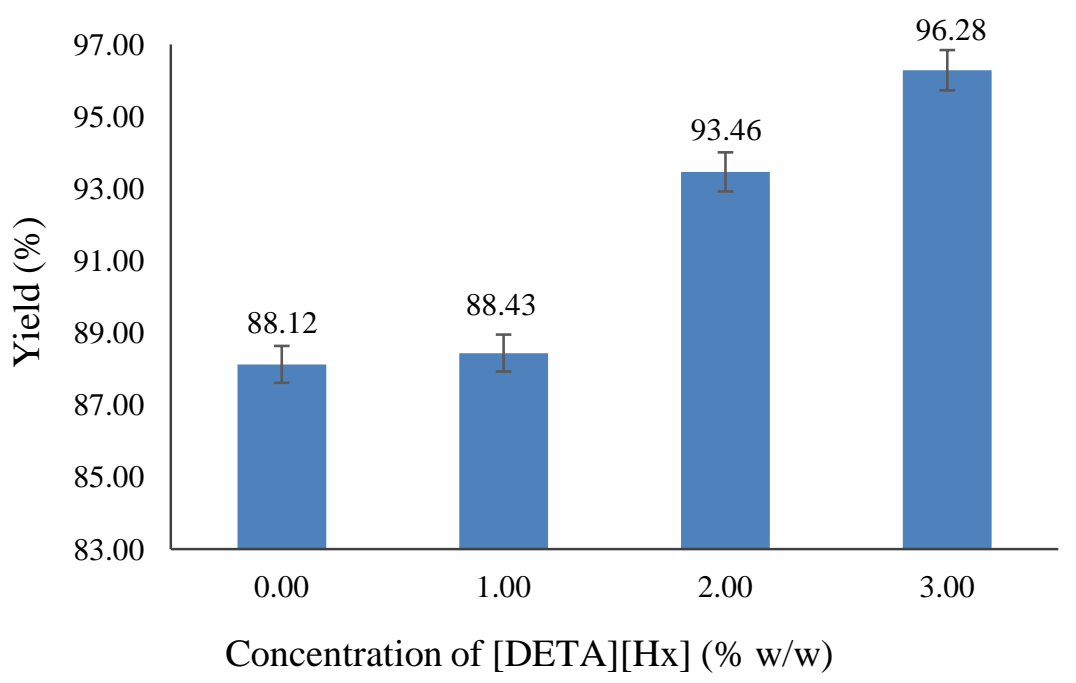

Figure 3. Biodiesel yield with different concentrations of [DETA][Hx] in 60 min of reaction.

\subsection{Analysis of biodiesel samples}

Figure 3 shows that increasing the concentration of [DETA] $[\mathrm{Hx}]$ as co-solvent in the alkaline transesterification of soybean oil provided higher yields of biodiesel. According to Muhammad et al. (2014), the ionic liquid, due to moderate surface tension, favors greater solubility between oil and methanol phases, accelerating the reaction rate and improving the yield of biodiesel.

In 60 minutes, a significant improvement in biodiesel yield was observed by increasing the amount of $[D E T A][H x]$ in the reaction medium, reaching a biodiesel yield increase of $8.16 \%$ when using $3 \%(w / w)$ of ionic liquid. Many co-solvents can be used to enhance miscibility among the reagents of the oil transesterification reaction in biodiesel. However, the improvement of biodiesel production may be limited due to co-solvents physical properties, operating conditions, and undesirable reactions (Thanh et al., 2013). [DETA] $[\mathrm{Hx}]$ has a relatively low surface tension $(24.3 \mathrm{mN} / \mathrm{m})$ at $60^{\circ} \mathrm{C}$. This characteristic intensifies the mass transfer; therefore, it affects the interface area between reagents, enabling the solubility between the immiscible phases of oil and methanol.

Ruzich and Bassi (2010) used $4 \mathrm{~mL}$ of AlL [BMIM] $\left[\mathrm{PF}_{6}\right]$ as co-solvent in biodiesel production through enzymatic catalysis. The researchers obtained a maximum yield in ester content of $80 \%$ in $6 \mathrm{~h}$ of reaction. In comparison, the use of $3 \%$ $(w / w)$ of PIL [DETA][Hx] as co-solvent, which in volume amounts to approximately $3 \mathrm{~mL}$, provided 


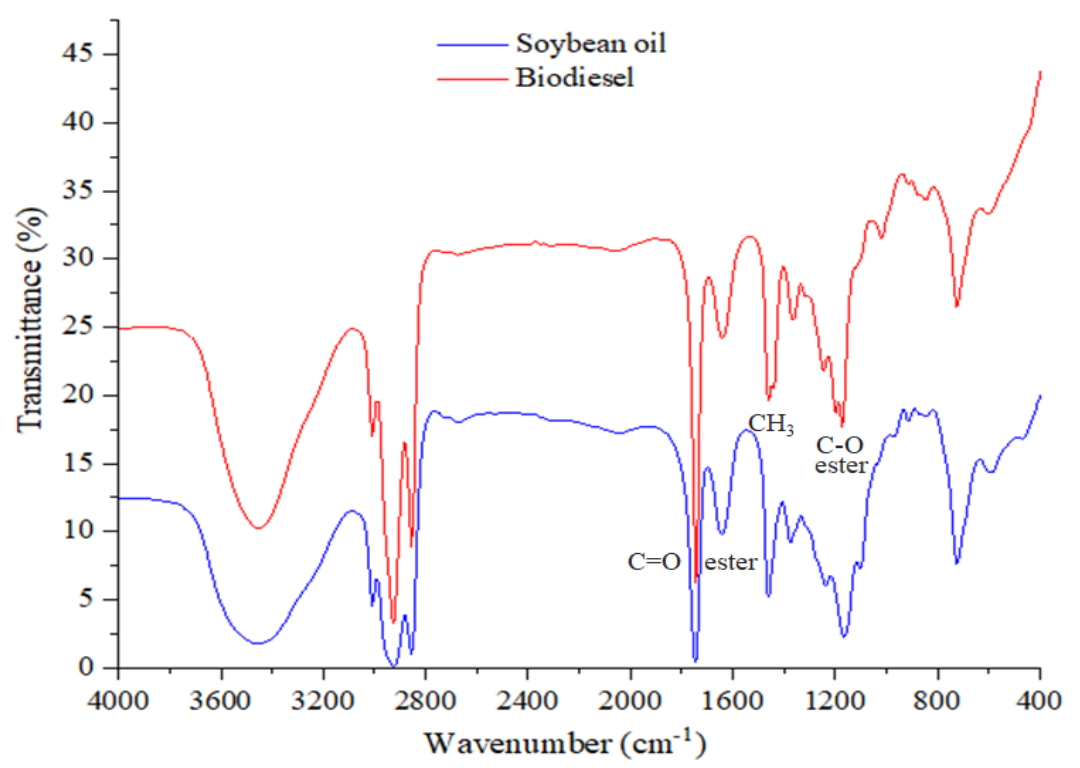

Figure 4. FTIR of soybean oil and biodiesel.

the highest yields (up to $16 \%$ higher) with lower reaction time, exhibiting greater efficiency for this purpose.

FTIR spectra of crude soybean oil and biodiesel were performed in the range of 4000 to $400 \mathrm{~cm}^{-1}$ with Fourier Transform Infrared. Figure 4 shows an equivalent pattern for the combined FTIR spectra of both compounds. This equivalency occurs due to the similarities between triglycerides and methyl ester in their functional groups. The variation in transmittance percentage and functional groups indicated the changes that occurred during the transesterification process.

According to Figure 4, there were no significant peaks in the regions between $1800-2800 \mathrm{~cm}^{-1}$ for soybean oil and biodiesel spectra. Both spectra showed strong peaks between 2800-3000 $\mathrm{cm}^{-1}$ corresponding to $\mathrm{C}-\mathrm{H}$ vibrations, and between $1700-1800 \mathrm{~cm}^{-1}$ equivalent to the stretching of the $\mathrm{C}=\mathrm{O}$ bond. The main differences are in the band of $1600-400 \mathrm{~cm}^{-1}$ and are defined mainly by esters because of $\mathrm{C}-\mathrm{O}$ vibrations. The strong ester peaks characterized around $1750 \mathrm{~cm}^{-1}(\mathrm{C}=\mathrm{O})$ and between 1170- $1200 \mathrm{~cm}^{-1}$ (C-O) are clearly present in the spectra. In addition to this, other characteristic peaks of biodiesel indicate the presence of $\mathrm{CH}_{3}$ group in methyl ester mixtures, and can be observed in the $1450 \mathrm{~cm}^{-1}$ range (Ezekannagha et al., 2017; Wembabazi et al., 2015).

To ensure product quality, some properties must be measured to comply with current specifications, meeting adequate biodiesel storage and commercialization standards. Table 2 indicates that the sample with $3 \%(\mathrm{w} / \mathrm{w})$ of co-solvent with the highest yield $(96.28 \%$ ) was analyzed in terms of

Table 2. Physicochemical properties of $3 \% \mathrm{w} / \mathrm{w}$ of $[\mathrm{DETA}][\mathrm{Hx}]$ in 60 minutes of reaction.

\begin{tabular}{cccccc}
\hline Properties & Biodiesel & ANP 45/2014 & EN 14214 & $\begin{array}{c}\text { ASTM } \\
\text { D6751 }\end{array}$ & Method \\
\hline Appearance & $\begin{array}{c}\text { Clear and free } \\
\text { of impurities }\end{array}$ & $\begin{array}{c}\text { Clear and } \\
\text { free of } \\
\text { impurities }\end{array}$ & - & - & - \\
$\begin{array}{c}\text { Specific gravity at } 20{ }^{\circ} \mathrm{C} \\
\left(\mathrm{kg} \cdot \mathrm{m}^{-3}\right)\end{array}$ & 884.2 & $850-900$ & $860-900$ & - & ASTM D4052 \\
$\begin{array}{c}\text { Kinematic viscosity at } \\
40{ }^{\circ} \mathrm{C}\left(\mathrm{mm}^{2} \mathrm{~s}^{-1}\right)\end{array}$ & 4.3526 & $3.0-6.0$ & $3.5-5.0$ & $1.9-5.0$ & ASTM D445 \\
Flash point $\left({ }^{\circ} \mathrm{C}\right)$ & 170 & $\begin{array}{c}\text { Minimum of } \\
100\end{array}$ & $\begin{array}{c}\text { Minimum of } \\
101\end{array}$ & $\begin{array}{c}\text { Minimum of } \\
130\end{array}$ & ASTM D93 \\
\hline
\end{tabular}


specific gravity, kinematic viscosity, and flash point to verify compliance with the requirements of EN 14214 (2012), ASTM D6751 (2007), and ANP 45/2014 (2014).

Table 2 shows that the biodiesel produced follows the standards specified by European, American, and Brazilian regulations, indicating that the production of biodiesel using [DETA] $[\mathrm{Hx}]$ as cosolvent was satisfactory in terms of the aforementioned properties.

\section{CONCLUSIONS}

The enhancement of PIL [DETA][Hx] mass concentration as co-solvent in biodiesel production favored a significant increase in reaction yield, reaching $96.28 \%$ for a concentration of $3 \%(\mathrm{w} / \mathrm{w})$ of co-solvent in $60 \mathrm{~min}$ of reaction. When compared to the yield of the sample without co-solvent, an increase of $8.16 \%$ is observed. Literature indicates that AlLs are used frequently as catalysts in biodiesel production, but higher amounts of this compound are required in the reaction. In addition, AlLs are costlier and more toxic than PILs. Based on the results obtained, it was possible to assess that the use of [DETA] $[\mathrm{Hx}]$ as co-solvent in the biodiesel production is a promising alternative to traditional catalysts, since the properties analyzed indicate that biodiesel complies with EN 14214 (2012), ASTM D6751 (2007), and ANP 45/2014 (2014) standards.

\section{ACKNOWLEDGMENTS}

This study was financed in part by the Coordenação de Aperfeiçoamento de Pessoal de Nível Superior - Brasil (CAPES) - Finance Code 001. Author S. Mattedi acknowledges the support provided by CNPq (Grant 306640/2016) and FAPESB/SECTI (Project APP0075/2016).

\section{REFERENCES}

ABNT NBR 11115. Insumos - Substâncias Graxas - Determinação do Índice de Acidez. Associação Brasileira de Normas Técnicas, 2014.
Andreani, L.; Rocha, J.D. Use of ionic liquids in biodiesel production: A review. Brazilian Journal of Chemical Engineering. v. 29, p. 1-13, 2012. https://doi.org/10.1590/S0104-66322012000100001

ANP. Agência Nacional do Petróleo, Gás Natural e Biocombustíveis. Available at: http://www.anp.gov.br. Accessed on: 09 November 2018. (in Portuguese)

ANP 45/2014. Especificações do biodieselResolução ANP № 45, Agência Nacional de Petróleo, Gás Natural e Biocombustíveis. - DOU 26.8.2014 - 2014. (in Portuguese)

ANVISA. Guia de controle de qualidade de produtos cosméticos. Agência Nacional de Vigilância Sanitária, 2008. (in Portuguese)

ASTM D4052. Standard Test Method for Density, Relative Density, and API Gravity of Liquids by Digital Density Meter. ASTM International, West Conshohocken, PA, 2016.

ASTM D445. Standard Test Method for Kinematic Viscosity of Transparent and Opaque Liquids (and Dynamic Viscosity). ASTM International, West Conshohocken, PA, 2017.

ASTM D6751. Standard Specification for Biodiesel Fuel Blend Stock (B100) for Middle Distillate Fuels. ASTM International, West Conshohocken, PA, 2007.

ASTM D93. Standard Test Methods for Flash Point by Pensky-Martens Closed Cup Tester. ASTM International, West Conshohocken, PA, 2016.

ASTM D971. Standard Test Method for Interfacial Tension of Oil Against Water by the Ring Method. ASTM International, West Conshohocken, PA, 2012.

Basha, S.A.; Gopal, K.R.; Jebaraj, S. A review on biodiesel production, combustion, emissions and performance. Renewable and Sustainable Energy Reviews, v.13, p. 1628-1634, 2009. https://doi.org/10.1016/i.rser.2008.09.031

EN 14214. Liquid Petroleum Products - Fatty Acid Methyl Esters (FAME) for use in Diesel Engines and Heating Applications - Requirements and Test Methods. European Standards, Brussels, Belgium, 2012. 
Encinar, J.M.; Pardal, A.; Sánchez, N. An improvement to the transesterification process by the use of co-solvents to produce biodiesel. Fuel. v. 166, p. 51-58, 2016.

https://doi.org/10.1016/i.fuel.2015.10.110

Ezekannagha, C.B.; Ude, C.N.; Onukwuli, O.D. Optimization of the methanolysis of lard oil in the production of biodiesel with response surface methodology. Egyptian Journal of Petroleum. v. 26, p. 1001-1011, 2017.

https://doi.org/10.1016/i.ejpe.2016.12.004

Ghiaci, M.; Aghabarari, B.; Habibollahi, S.; Gil, A. Highly efficient Brønsted acidic ionic liquid-based catalysts for biodiesel synthesis from vegetable oils. Bioresource Technology. v. 102, p. 12001204, 2011.

https://doi.org/10.1016/i.biortech.2010.09.095

Keera, S.T.; El Sabagh, S.M.; Taman, A.R. Transesterification of vegetable oil to biodiesel fuel using alkaline catalyst. Fuel. v. 90, p. 42-47, 2011. https://doi.org/10.1016/i.fuel.2010.07.046

Knothe, G.; Razon, L.F. Biodiesel fuels. Progress in Energy Combustion Science, v. 58, p. 36-59, 2017. https://doi.org/10.1016/i.pecs.2016.08.001

Leung, D.Y.C.; Wu, X.; Leung, M.K.H. A review on biodiesel production using catalyzed transesterification. Applied Energy, v. 87, p. 10831095, 2010.

https://doi.org/10.1016/i.apenergy.2009.10.006

Lima, J. R. D. O.; Ghani, Y. A.; Da Silva, R. B.; Batista, F. M. C.; Bini, R. A.; Varanda, L. C.; De Oliveira, J. E. Strontium zirconate heterogeneous catalyst for biodiesel production: Synthesis, characterization and catalytic activity evaluation. Applied Catalysis A: General, v. 445-446, p. 76-82, 2012. https://doi.org/10.1016/i.apcata.2012.08.005

Mohamad, M.; Ngadi, N.; Wong, S.L.; Jusoh, M.; Yahya, N.Y. Prediction of biodiesel yield during transesterification process using response surface methodology. Fuel, v. 190, p. 104-112, 2017. https://doi.org/10.1016/i.fuel.2016.10.123

Moro, M. K.; Andreatta, D.; Oliveira, B. C.; Bimbato, R. M.; Simonelli, G. Application of central composite rotational delineation (CCRD) in the study of biodiesel properties. Brazilian Journal of Petroleum and Gas, v. 11, p. 187-195, 2017. https://doi.org/10.5419/bipg2017-0016
Muhammad, N.; Elsheikh, Y. A.; Mutalib, M. I. A.; Bazmi, A. A.; Khan, R. A.; Khan, H.; Rafiq, S.; Man, Z.; khan, I. An overview of the role of ionic liquids in biodiesel reactions. Journal of Industrial and Engineering Chemistry, v.21, p. 1-10, 2015. https://doi.org/10.1016/i.jiec.2014.01.046

Olivier-Bourbigou, H.; Magna, L.; Morvan, D. lonic liquids and catalysis: Recent progress from knowledge to applications. Applied Catalysis A: General, v. 373, p. 1-56, 2010.

https://doi.org/10.1016/i.apcata.2009.10.008

Pinto, R. R.; Santos, D.; Mattedi, S.; Aznar, M. Density, refractive index, apparent volumes and excess molar volumes of four protic ionic liquids + water at $\mathrm{T}=298.15$ and $323.15 \mathrm{~K}$. Brazilian Journal of Chemical Engineering, v. 32, p. 671-682, 2015. https://doi.org/10.1590/0104$\underline{6632.20150323 s 00003444}$

Rafiee, E.; Mirnezami, F. Temperature regulated Brønsted acidic ionic liquid-catalyze esterification of oleic acid for biodiesel application. Journal of Molecular Structure, v. 1130, p. 296-302, 2017. https://doi.org/10.1016/i.molstruc.2016.10.049

Ruzich, N. I.; Bassi, A. S. Investigation of enzymatic biodiesel production using ionic liquid as a co-solvent. The Canadian Journal of Chemical Engineering, v. 88, p. 277-282, 2010.

https://doi.org/10.1002/cjce.20263

Santos, D.; Lourenço, É.; Santos, M. F. C.; Franceschi, E.; Dariva, C.; Barison, A.; Zuber, A.; Castier, M.; Mattedi, S. Volumetric properties of binary aqueous solutions of protic ionic liquids based on bis (2-hydroxyethyl) ammonium. Journal of Molecular Liquids, v. 222, p. 867-872, 2016. https://doi.org/10.1016/j.molliq.2016.07.048

Santos, O. O.; Maruyama, S. A.; Claus, T.; de Souza, N. E.; Matsushita, M.; Visentainer, J. V. A novel response surface methodology optimization of base-catalyzed soybean oil methanolysis. Fuel, v. 113, p. 580-585, 2013.

https://doi.org/10.1016/i.fuel.2013.06.011

Thanh, L. T.; Okitsu, K.; Sadanaga, Y.; Takenaka, N.; Maeda, Y.; Bandow, H. A new co-solvent method for the green production of biodiesel fuel Optimization and practical application. Fuel, v. 103, p. 742-748, 2013.

https://doi.org/10.1016/i.fuel.2012.09.029 
Vafaeezadeh, M.; Alinezhad, H. Brønsted acidic ionic liquids: Green catalysts for essential organic reactions. Journal of Molecular Liquids, v. 218, p. 95-105, 2016.

https://doi.org/10.1016/i.molliq.2016.02.017

Van Gerpen, J. Biodiesel processing and production. Fuel Processing Technology, v. 86, p. 1097-1107, 2005.

https://doi.org/10.1016/j.fuproc.2004.11.005

Varatharajan, K.; Pushparani, D. S. Screening of antioxidant additives for biodiesel fuels. Renewable and Sustainable Energy Reviews, v. 82, p. 2017-2028, 2018.

https://doi.org/10.1016/i.rser.2017.07.020
Wembabazi, E.; Mugisha, P. J.; Ratibu, A.; Wendiro, D.; Kyambadde, J.; Vuzi, P.C. Spectroscopic analysis of heterogeneous biocatalysts for biodiesel production from expired sunflower cooking oil. Journal of Spectroscopy, v. 2015, Article ID 714396, p. 1-8, 2015.

https://doi.org/10.1155/2015/714396 